\title{
La narrativa como método desencadenante y producción teórica en la investigación cualitativa
}

\author{
Narrative as elicitation method and theoretical production \\ in qualitative research
}

\author{
Rosario García-Huidobro Munita \\ Universidad de Barcelona \\ rosarioghm@gmail.com (ESPAÑA)
}

Recibido: 15.082015
Aceptado: 10.05 .2016

\section{RESUMEN}

En este artículo se comparte el lugar que se ha dado a los relatos y la narrativa como método y formas de saber en una investigación doctoral. Para ello se desarrolla una genealogía entre la metodología narrativa y la Investigación Basada en las Artes (IBA). Este cruce permite comprender el giro narrativo en las ciencias sociales y sus aportes a la investigación cualitativa, sobre todo las contribuciones de los métodos artísticos y literarios en la investigación de la experiencia educativa. Tras este recorrido, a modo de ejemplo se comparten tres formas en las se utilizó el relato durante la recogida de evidencias para este estudio doctoral. Primero, el relato como estrategia desencadenante para las entrevistas. Luego, como método visual y desencadenante para los focus group y, por último, como construcción teórica de análisis, a través de la construcción de narraciones biográficas. Estas tres formas, que poseen elementos de la Investigación Basada en las Artes, fueron utilizadas como estrategias para comprender el saber docente de un grupo de profesoras de artes visuales en Chile.

\section{PALABRAS CLAVE}

Relato, metodología, investigación narrativa, investigación basada en las artes, narrativas biográficas 


\begin{abstract}
In this article we share the place that we gave to the tales and narrative as method and forms of knowledge in a doctoral research. For this a genealogy between narrative methodology and Arts Based Research (IBA) is developed. This crossing allows to understand the narrative turn in the social sciences and their contributions to qualitative research, especially the contributions of literary and art research methods in the educational experience. After this tour, as an example, we share three forms of how the account was used during the collection of evidence for this doctoral study. First, the story as a trigger strategy for interviews. Then, as visual method and trigger for focus group and, finally, as a theoretical construction of analysis, through the construction of biographical narratives. These three forms, which have elements of Arts Based Research, were used as strategies to understand the teacher knowledge of a group of art teachers in Chile.
\end{abstract}

\title{
KEY WORDS
}

Tale, methodology, narrative research, arts based research, biographical narratives.

\section{INTRODUCCIÓN}

Este escrito surge de la presentación realizada para el International Summer Workshop on Alternative Methods in Social Research, que se llevó a cabo en la Universidad de Barcelona, en Julio del 2015.

Esta exposición se enmarcó en la investigación doctoral que se desarrolla en el programa Artes y Educación de la misma universidad. En este estudio, el objetivo principal ha sido comprender cómo cuatro mujeres artistas y docentes de artes en Chile, han ido conformando y relacionándose con sus saberes docentes a lo largo de su historia personal y profesional, desde sus sentidos como mujeres y sus prácticas artísticas. Para ello, se generó una vinculación entre sus vivencias como mujeres, artistas y docentes, donde el relato como método, fenómeno, evidencia y elaboración teórica tomó un rol protagónico.

Para lograr dicha propuesta, el primer objetivo específico estuvo ligado a la metodología biográfica narrativa, pues, se buscó comprender de qué manera el acto de relatar y compartir narrativamente sus experiencias develaba aspectos de sus saberes docentes y se articulaba como herramienta que contribuía al desarrollo profesional. Así mismo, el segundo objetivo de este estudio fue generar espacios de saber compartido sobre la enseñanza artística, desde el diálogo y la escucha, a partir de la relación entre las maestras y que pudiera contribuir a su desarrollo profesional. 
En relación a estos dos objetivos específicos, desde el inicio fue fundamental preguntarse qué significaba, para estas maestras, relatar sus experiencias y trayectos de saber. Por ello, se buscó abrir un espacio de re-interpretación desde la narrativa y el acto de relatarse, por lo que lo narrativo se situó como epistemología y metodología en la investigación. Este espacio y acto permitió reflexionar, tanto para ellas como para la investigadora, cómo iban conformando constantemente sus identidades, desde el tránsito entre sus roles y posicionamientos como mujeres artistas y profesoras.

Para profundizar el lugar que se otorgó al relato - como objetivo principal de este artículo - primero será importante revisar la perspectiva metodológica con la cual se sitúa este estudio. También se explicarán las etapas de recogida de evidencias, para que en los siguientes apartados — donde se profundizan las tres formas en que se utilizó el relato- se comprenda el contexto de estudio y el trabajo realizado con las maestras para dicha investigación cualitativa.

La perspectiva narrativa desarrollada en este estudio ha sido fundamental, pues ha sido un posicionamiento epistemológico y herramienta metodológica que ayudó a valorar, comprender, cuestionar y visibilizar los recorridos de estas mujeres, pues centrarse en sus relatos permitió entenderlos como fuentes de saberes. Para ello, y como proponen Jean Clandinin y Michael Connelly, (1990, 1995, 2000), se problematizó la narrativa como fenómeno de estudio y método, pero a su vez, también como resultado. Es decir, como construcción teórica final, pues desde una perspectiva narrativa y literaria se reconstruyó las historias de saber estas maestras. Esta manera de situar y utilizar el relato en este estudio, así también en la recogida de evidencias, llevó a revisar y cuestionar el papel del relato en las investigaciones sociales. Por ello, se comenzó a dialogar con la posición que la Investigación Basada en las Artes (IBA) toma respecto a la utilización del relato y la narrativa (Barone y Eisner, 2006).

Para contar cómo se transitó entre la perspectiva narrativa y la IBA, brevemente se explica el proceso de recogida de evidencias, el cual se desarrolló en dos etapas.

La primera parte de esta investigación se llevó a cabo a través de la plataforma mujeresartistasdocentes.org ${ }^{1}$ A partir del modelo de años de experiencia profesional planteado por Michael Huberman (1989), se invitó a un grupo de profesoras chilenas ${ }^{2}$ que vivieran entre las etapas de 'estabilización'

1 Para desarrollar un recorrido más profundo sobre esta primera etapa se recomienda revisar el artículo "Compartir experiencias entre mujeres, artistas y docentes a través de herramientas virtuales", en García-Huidobro, 2014).

2 Para esta investigación participaron cuatro profesoras de artes chilenas, que además de enseñar en la escuela secundaria desarrollaban un tipo de práctica artística personal. Este perfil ayudaba a entender los desplazamientos entre su hacer artístico y el docente, noción que James Adams (2003) llama 'artist-teacher shame'. El perfil de las cuatro profesoras era variado. Dos de ellas eran Licenciadas en Artes Visuales con estudios posteriores de educación. Otra de las participantes era Licenciara en Artes e inmediatamente comenzó a trabajar sin obtener estudios especializados sobre la enseñanza, por lo que ésta la fue aprendiendo en cursos de perfeccionamiento docente. Por último, el cuarto caso fue una maestra que estudió Licenciatura en Educación con mención en Artes Visuales. La variedad de los cuatro casos aportaron diversas evidencias y experiencias que 
(entre los cuatro y seis años de desarrollo profesional) y 'diversificación/ cuestionamientó (entre los 7 y 25) a narrar y compartir diversas vivencias en el espacio virtual. Durante un período de tres meses se llevó a cabo un estudio asincrónico. Cada semana, y a partir de diversas preguntas específicas, el grupo compartía cómo transitaban entre las artes y la educación (García-Huidobro, 2014).

Luego, la segunda etapa de recogida de evidencias fue presencial. Tras desarrollar un primer análisis sobre los relatos virtuales se realizaron seis entrevistas semi-estructuradas con el mismo grupo de participantes y dos focus group con este grupo de maestras. Además se asistió durante un período a sus prácticas docentes. En esos acompañamientos se observaba cómo las maestras se relacionaban con sus diversos saberes y cómo los compartían con sus estudiantes. Para ello el diario etnográfico fue relevante, pues era la herramienta que permitía desarrollar los relatos de sus saberes experienciales (Tardif, 2004). Estos tres métodos fueron estrategias importantes para acercarse a comprender sus saberes docentes, por lo que se puso énfasis en lo narrativo, es decir, en cómo se contaban: sus palabras, gestos y emociones.

Si bien para el análisis — codificación y conformación de las categorías - se utilizaron herramientas de la segunda generación de la Teoría Fundamentada (Charmaz, 2006, 2012), la perspectiva narrativa como metodología siguió siendo el hilo, ese que permitía relacionar y visibilizar sus relatos como formas de subjetividad (Petra Munro, 1998). Utilizar algunas herramientas de la Teoría Fundamentada para el análisis ayudó a ordenar las evidencias y construir cuatro categorías ${ }^{3}$ que permitieron generar comprensiones sobre sus modos de conformar sus saberes docentes y, posteriormente, reconstruir sus narraciones biográficas.

El trabajo final de esta investigación se develó a través de una narración biográfica por cada maestra. La construcción de éstas implicó cruzar distintas herramientas y técnicas narrativas puesto que, al igual que Bárbara Biglia y Jordi Bonet-Martí (2009), se buscaron nuevas formas de construir narrativas y mostrar los saberes de estas maestras, dando prioridad en maneras de escritura más compartidas y relacionales. Además, este modo de construir los relatos que desafía la escritura académica - conlleva aspecto narrativos que se ligan a las dimensiones literarias. Por ende, como señalan Tom Barone y Elliot Eisner (2006), se adentran al terreno de la Investigación Basada en las Artes (IBA).

En este sentido, debido a la importancia que en este estudio adoptó el relato

enriquecieron la investigación.

Las categorías del saber docente que surgieron tras el análisis fueron: (1) el lugar del conflicto, (2) del no-saber, (3) de los otros y otras y (4) del agenciamiento en el saber docente. Para un recorrido más extenso se recomienda leer "El espacio entre. Saberes docentes de mujeres artistasdocentes" (en García-Huidobro, 2015a).

${ }^{3}$ Las categorías del saber docente que surgieron tras el análisis fueron: (1) el lugar del conflicto, (2) del no-saber, (3) de los otros y otras y (4) del agenciamiento en el saber docente. Para un recorrido más extenso se recomienda leer "El espacio entre. Saberes docentes de mujeres artistasdocentes" (en García-Huidobro, 2015a). 
como texto literario, tanto para las entrevistas, focus group y construcción de las narraciones biográficas, en el siguiente apartado se comparte el lugar que el relato ha ganado, tanto en la investigación narrativa, como en la IBA. Luego se exponen tres ejemplos sobre el uso del relato como estrategia para comprender el saber docente de las profesoras de este estudio.

\section{EL RELATO EN LA INVESTIGACIÓN NARRATIVA Y LA INVESTIGACIÓN BASADA EN LAS ARTES}

El objetivo de este es hacer una breve revisión literaria sobre cómo se ha situado el relato en ambas perspectivas, buscar cómo se relacionan y nutren mutuamente para luego ejemplificarlo a través del presente estudio.

Para ello, primero hubo un acercamiento a la perspectiva de investigación narrativa, ya que permite dar nuevos significados a nuestras experiencias (Bruner, 2004; Candinin y Conelly, 1990, 1995, 2000; Goodson, 2010, entre otros).

Cuentan Denzin y Lincoln (2011) que esta perspectiva de investigación surgió a partir del interés y necesidad de otras maneras de comprender y contar el comportamiento humano, pues, permite rescatar los valores de la subjetividad y re-valorar la práctica de hablar y narrar cómo una manera de comprender el significado que otorgamos a nuestra forma de percibir el mundo. Así, a partir de estas nuevas búsquedas en investigación social y acompañado por el giro narrativo, promovido a finales de los setenta, se comenzó a recuperar relatos olvidados y explorar diversas formas de escritura, que respondieran a la crisis de los grandes relatos hegemónicos.

Frente a este desafío, la investigación narrativa propuso cuatro temas que respondieron a un giro, en relación al modo de pensar la investigación social. El primer cambio apuntó a la relación entre investigador e investigado, para señalar la importancia de que ambos están en relación y construyen en conjunto la investigación (Clandinin, 2007). Por otro lado, este tipo de investigación permitió una mayor aceptación y apertura a modos diversos y alternativos de conocer. Un tercer cambio supuso comprender las experiencias particulares, desde lugares y contextos específicos. Desde aquí que las investigaciones feministas se han identificado y han promovido las investigaciones narrativas, lo que según Antonio Bolívar (2002) conduce a considerar esta perspectiva como una forma específica y política del discurso femenino. Por último, este nuevo enfoque unido a los planteamientos posestructuralistas, promovió un giro que fue desde el uso de los números al uso de las palabras como datos o evidencias. Con ello se dio prioridad no solo a lo vivido como evidencia, sino a las palabras y la narrativa como método y estrategia para investigar y dar nuevos significados.

Como para la investigación que se comparte en este escrito era de interés comprender el saber docente de un grupo de maestras, desde lo narrativo, nos acercamos a la noción de experiencia como un saber que está intrínsecamente involucrado en nuestra vida y la narración (Bruner, 2004). 
De este modo, para este estudio se comprendió la narrativa como una forma de pensar y comprender la realidad y, segundo, como espacio de construcción como sujetos, es decir, como fuente epistemológica y ontológica. Desde aquí que se adoptó la narrativa como un saber que está enraizado en nuestras experiencias y modo de relacionarnos. También como un camino para aprender a pensarnos y conocernos (Bruner, 1990) e ir trazando los discontinuos trayectos del saber. Así se fue adoptando la narrativa como una forma y posibilidad de aprendizaje, pues, Ivor Goodson (2010) presenta lo narrativo no solo como una posibilidad para aprender, desde las historias que contamos y reflexionamos sobre nuestra vida, sino como un aprendizaje contingente que sucede durante el proceso de quien se cuenta.

¿Cómo a partir de la reflexión y la escucha, sobre nuestros relatos y de los otros(as), vamos aprendiendo y se va generando la experiencia de saber? Desde estos cuestionamientos la práctica narrativa fue confluyendo como perspectiva epistemológica y metodológica en la investigación cualitativa (Denzin y Lincoln, 2011). Adoptar esta metodología significa comprender la narrativa como herramienta que, por un lado, nos ayuda a cuestionar la realidad desvelando los posibles significados de lo vivido y, por otro, se despliega como un espacio reflexivo para pensar y aprender (Goodson, 2010), donde el investigador(a) se incluye en el relato para ir dando cuenta del proceso a través de sus desplazamientos (Hernández, s/f).

Además, sobre esta última idea, Fernando Hernández (s/f) ha contado desde su trayectoria por la investigación narrativa, que los relatos que construyen y experimentan los investigadores pueden ser (1) de carácter memorialista para describir de la realidad, (2) también se puede utilizar el relato como dato o evidencia que se pone en contexto o relación con la voz de otros autores, o bien, (3) se puede utilizar como herramienta de diálogo interpretativo. Es decir, utilizar el relato como herramienta discursiva y reflexiva que permita conversar con los relatos para generar nuevos saberes.

A partir de estas ideas, el relato puede ser utilizado de diversas maneras en la investigación cualitativa. Como en esta investigación la narrativa fue vinculada a la investigación basada en las artes (IBA), a continuación se realiza un recorrido por esta perspectiva.

La IBA se ha nutrido desde los cuestionamientos que la perspectiva construccionista (Gergen, 1996) y el giro narrativo (Bruner, 1990) han desarrollado sobre nuevas y otras formas de comprender el mundo social. A partir de éstas se cuestiona el modo tradicional y positivista de investigación y busca nuevas formas de entender la construcción social, el conocimiento y las formas de investigar. Muy importante, en esta línea, han sido los aportes de Elliot Eisner (1998), quien ha postulado nuevas formas de entender el conocimiento, como aquellas que pueden provenir de la experiencia y, sobre todo, de la artística. En esta línea, la IBA ha sido una metodología que se ha interesado por comprender, desde Eisner y Barone (2006), cómo las artes pueden dar cuenta de un proceso de investigación y/o ser parte de la misma.

Así, esta metodología cualitativa se apoya en procedimientos y experiencias 
artísticas (literarias, visuales, performativas, musicales) para comprender y dar cuenta de otros fenómenos sociales, como también utiliza estrategias que permiten mostrar aspectos que, a veces, con otros métodos no se pueden dar cuenta (Hernández, 2008). Así también, para las académicas feministas Ephrat Huss y Julie Cwikel (2005), la IBA se puede utilizar como método, como forma de análisis, una temática, o todo a la vez, ya que permite nuevas formas de comprender y profundizar lo vivido. Además, para estas académicas, adoptar esta perspectiva de investigación empodera a los entrevistados, lo que ayuda a igualar las relaciones entre investigador(a) e investigado.

Por otro lado, Mason (2002) y Sclater (2003) consideran que, en la IBA, tanto los dibujos, como las historias, relatos, viñetas o fotografías pueden ser utilizados como estrategias desencadenantes en las entrevistas y además como una forma que puede ayudar a vincular conceptos abstractos.

Lo que estos autores mencionan ha sido relevante en esta investigación, ya que se ha optado por utilizar la narrativa como un modo que permitió organizar, dar coherencia y significado, tanto al relato del proceso de investigación, como a las experiencias que se vivió con las maestras. Así, por ejemplo y como señalan Barone y Eisner (2006), el tipo de texto que se vincula a la IBA es aquel que desafía los convencionales ya que tiende a relacionarse más con lo literario que con la escritura académica, objetiva y poco evocativa.

Estos autores señalan que los tipos de textos que acompañan a estas investigaciones suelen describir y contar, a modo de historia y anécdota, el proceso de la investigación. El texto literario que encabeza estos estudios se vincula a la poesía, ensayos, novelas, biografías, etc., y suelen utilizar un tipo de lenguaje evocativo, contextual y 'vernacular'.

Por ejemplo, un tipo de lenguaje literario que es evocativo suele ser más expresivo y connotativo que meramente descriptivo y denotativo. Es una escritura que estimula las facultades imaginativas del lector, incitándolo a que pueda situarse en la experiencia y reinterpretarla. También, utilizar un lenguaje contextual, a través de las metáforas y descripciones densas, ayuda a recrear el ambiente para que quien lo lea pueda vivirla. Por último, un texto 'vernacular' toma en cuenta las expresiones de la gente y lo vivido, por lo que este texto utiliza el lenguaje que fue vivido en la experiencia.

En este sentido, el tipo de texto y lenguaje que se utiliza en la IBA toma una vinculación estrecha con la perspectiva narrativa de investigación (Barone y Eisner, 2006), por ende, ambas visiones se nutren ya que, como estos autores postulan, la construcción narrativa o el storytelling se articula como forma, tipo y hasta resultado de investigación.

Desde este entrecruce de ideas — entre la perspectiva narrativa y la IBAa continuación comparto tres ejemplos de cómo, en este estudio, se utilizó la narrativa en tanto estrategia más orientada a lo literario, por ser textos vernaculares, contextuales y evocativos que pusieron en el centro aspectos dialógicos y el cruce de relatos vividos para comprender el problema del saber. 


\section{EL RELATO COMO ESTRATEGIA DESENCADENANTE PARA LAS ENTREVISTAS}

Este primer ejemplo se sitúa en la recogida de evidencias que se desarrolló a través de las entrevistas. Para ello se realizaron seis entrevistas con cada profesora. Las primeras cuatro estaban enfocadas en sus aspectos biográficos y las dos últimas en sus prácticas pedagógicas, por lo que estuvieron ligadas al período de acompañamiento a sus trabajos en las escuelas, lo que Maurice Tardif (2004) llama el saber experiencial ${ }^{4}$ de los y las maestras.

Para desarrollar estas dos últimas entrevistas, durante el período de acompañamiento a sus prácticas docentes se tomaron notas, en un diario de campo, de los aspectos y situaciones más relevantes y que pudieran relacionarse con las formas en que se habían relatado en las entrevistas anteriores. Así, como el objetivo de las dos últimas entrevistas era dialogar acerca de su saber experiencial - aquel que se arraigaba en sus práctica en el aula y con los estudiantes-, se transformaron las notas de campo en relatos etnográficos que describían de modo evocativo, contextual y vernacular (Barone y Eisner, 2006), cómo las maestras se movían, enseñaban, relacionaban con los estudiantes y sus saberes personales y artísticos.

Estos relatos fueron utilizados, como han apuntado Mason (2002) y Sclater (2003), para promover nuevos relatos en las entrevistas, como una estrategia para que pudiesen reflexionar sobre su práctica docente. A partir de las notas de campo el desafío fue transformarlos en relatos que captaran y expresaran fielmente lo que sucedía en el aula, y que lejos de hacer juicios de valor sobre sus acciones, recogieran el episodio o escena vivida, respetando el lenguaje y ambiente de lo que acontecido.

En éstos, las profesoras siempre fueron las protagonista de los relatos y la investigadora se situaba como narradora observadora o de personaje secundario. Estas narraciones fueron leídas conjuntamente, con cada maestra, en las últimas entrevistas. Luego de estas lecturas se les hacía preguntas para profundizar en aquellas experiencias y relacionarlas con las anteriores entrevistas y sus fuentes de saberes. En otras ocasiones, más que hacerles preguntas concretas, simplemente se les pedía que expresaran cómo habían vivido aquella situación relatada en el aula.

En el siguiente cuadro (1) se comparte un ejemplo del relato que se leyó para la penúltima entrevista, con una de las participantes y, posteriormente, la pregunta que a partir de lo leído se le realizó. Estas narraciones se presentaron

${ }^{4}$ Para Maurice Tardif (2004) el saber experiencial se origina en la práctica cotidiana y es el núcleo vital del saber docente, aspecto que remarca como "epistemología de la práctica docente". Corresponden a los saberes que los profesores construyen al actualizar y dar sentido a los saberes anteriores en su trabajo cotidiano. Estos saberes no están basados en teorías o doctrinas (como los saberes procedentes de la formación profesional, el saber curricular o de los programas y libros didácticos) sino que son prácticos, interactivos, temporales y abiertos. Es un saber transversal, que se va conformando a partir de su experiencia, de conectar y dar sentido a sus otros saberes en la práctica cotidiana. 
como espacios donde las maestras podían pensarse a si mismas profesionalmente y además ligarlo a los aspectos personales para ir revelando nuevos saberes.

Leer en voz alta y de manera conjunta estos relatos, no solo era una forma dinámica para desarrollar estos encuentros, también una forma que permitía revivir la escena vivida, recordar emociones y relacionar estas experiencias con otras de manera reflexiva. Sobre el ejemplo que se comparte, dicho relato permitió que la profesora recordara y contara, a modo de anécdota, cómo el trabajo de esa niña le había llevado a desarrollar el suyo, una importante evidencia para el problema de investigación. Que compartiera estas vivencias y pensamientos eran aspectos fundamentales para este estudio, pues, a partir del nuevo relato que desarrolló comenzó a contar cómo transitaba de su práctica docente hacia su experiencia artística, lo que se presentaba como una importante evidencia sobre la conformación de su saber.

Como se muestra en el cuadro 1, la estrategia de compartir un relato etnográfico con la investigadora permite nuevas conversaciones y reflexiones sobre la propia práctica de la maestra. Es decir, como investigadores nos permite utilizar la narrativa para decir, contar, acentuar y visibilizar una cosa para iluminar algo más (Richardson, 1997). Lo que emerge refiere a los nuevos relatos y significados que surgen de lo reflexionado en conjunto. En este sentido, es una técnica que incluye capas de relatos entre las que se va reflexionando sobre el propio saber. Además, son estrategias que permiten mostrar las diversas posiciones, tanto de los y las participantes como de la investigadora, pues se visibiliza tanto la acción como la reflexión. 
Durante la última sesión, mientras las chicas trabajan en sus creaciones, la profesora se sentó en su escritorio y comenzó a evaluar los trabajos que habían entregado la clase anterior. De pronto se detuvo en uno y me comentó:

—Mira, que interesante este trabajo...me gusta este azul... —entonces giró la hoja para ver quién era la autora y cuál era el título de la obra.

- ¿Veraneando en Napas"?, ¿dónde estará eso? -me preguntó con curiosidad.

Entonces la profesora llama a la autora del trabajo y le pregunta

- (...) ¿Dónde está Napas?

— ¡Al sur! —dice la niña— jallí es donde yo voy a veranear!

-Debe ser bonito ahí... -responde la profesora.

I: ¿Qué piensas respecto a que, en esta actividad, las niñas hayan aprendido sobre los colores cálidos y fríos, a través de un paisaje que se relacione con sus experiencias personales?

P: Bueno, es lo que hago yo con mi pintura...claro, es como vincular el color con espacios, con lugares, con atmósferas. De hecho...jno me había dado cuenta!, pero el trabajo de esa niña, luego me motivó hacer un trabajo a mí...ese trabajo tenía una luna y un reflejo y después yo me di cuenta que llegué a mi casa a pintar una luna...ique loco!...

Cuadro 1: Transcripción entrevista con participante.

Es importante expresar que al escribir los relatos etnográficos se tuvo en cuenta que la escritura de un texto nunca es inocente y (Richardson y St. Pierre, 2005) menos puede ser leído de manera ingenua, ya que recrea verdades que - aunque sean parciales - es importante interrogar y no dar como supuestas (Gannon y Davies, 2012). Por ello, a partir de esta primera estrategia se utilizó la escritura como un cristal, pues, como experimenta Laurel Richardson (1997) permite mostrar múltiples formas de ser y estar, develando conflictos, incertidumbres, desplazamientos y descubrimientos tanto de la investigadora como de las propias participantes al ir reflexionando los relatos etnográficos.

Para terminar este apartado retomo la idea sobre la relación entre investigador e investigado ya que, a partir de las propuestas y prácticas feministas de estudio (Munro, 1998), el investigador(a) es considerado como mediador(a). Es decir, como quien a partir del diálogo con el otro u otra construye la investigación con sus colaboradores(as). Por ende, la sensibilidad y empatía con la cual debe afrontar estos encuentros es relevante, ya que estas características permiten que quienes colaboran se puedan abrir y compartir sus experiencias (García-Huidobro, 2013). 


\section{EL RELATO O TEXTO COMO DESENCADENANTE PARA LOS FOCUS GROUP}

Otra forma de utilizar el relato para la recogida de evidencias fue a través del focus group. Como se comentó anteriormente, uno de los objetivos específicos del estudio fue comprender de qué manera narrar y compartir experiencias entre el grupo de maestras develaba aspectos de sus saberes docentes y contribuía al desarrollo profesional. Si desde una perspectiva construccionista se propone que el saber es producido en conjunto, a partir de las interacciones sociales y en comunidad (Vivien Burr, 2003), entonces los focus groups se presentaron como un espacio para generar un saber y aprendizaje compartido.

Por otro lado, desde líneas feministas, se fomenta que a través del intercambio y el acto de escucharnos unas a otras, se abren puertas a las docentes que permitiría ampliar el desarrollo profesional de sus prácticas docentes y de sí mismas (Richert, 1993). En este sentido, se pensó que compartir experiencias narrativas podría ser una instancia o estrategia para comprender no solo de qué manera comparten y negocian su identidad en conjunto, sino que también como un espacio de encuentro y aprendizaje colectivo que apunta al desarrollo profesional. Como plantea Anna Richert (1993: 196): "escuchar las ideas de otros, tal como escuchar las propias ideas, entrega una poderosa oportunidad de aprendizaje". Sobre los encuentros, es importante recalcar que éstos no se desarrollaron como parte de una metodología de acción participativa, ya que las maestras fueron invitadas a compartir sus vivencias desde estrategias dialógicas y artísticas en relación a preguntas formuladas previamente por la investigadora. Más bien, como expresa Jennie Munday (2014) sobre los focus groups en investigaciones feministas, lo que prima de estos encuentros es la apertura al diálogo, la conversación abierta y que la investigadora no se sitúa en una posición de poder.

Para seguir estos objetivos se generaron dos instancias donde las participantes se reunieron, conocieron y compartieron sobre sus experiencias docentes. Para el primer encuentro grupal se dialogó sobre los diversos saberes que plantea Paulo Freire (2002). Así, para el segundo, el objetivo fue retomar los conversado en el primer focus group e intentar identificarse por lo que la otras compañeras compartieron en el primero encuentro grupal.

Para lograr el segundo objetivo, la investigadora imprimió múltiples veces, y en diversos tamaños, la transcripción de los diálogos del primer focus group. Estos fueron dispuestos de manera aleatoria arriba de la mesa (figura 1). También se dispuso otros materiales - como plumones, tijeras, cartulinas de colores, hojas blancas, flechas, etc.- para que cada maestra utilizara lo que quisiese. 

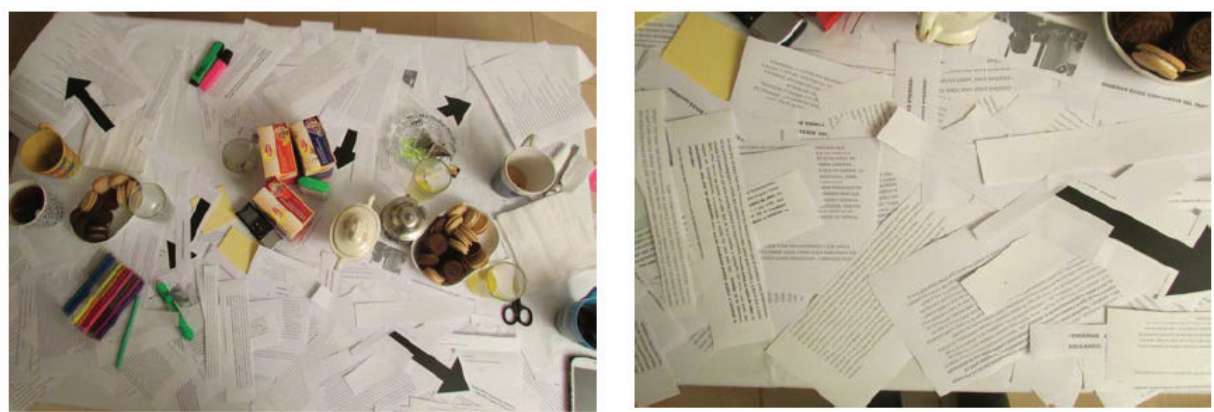

Figura 1: Impresiones de las transcripciones para el segundo focus group
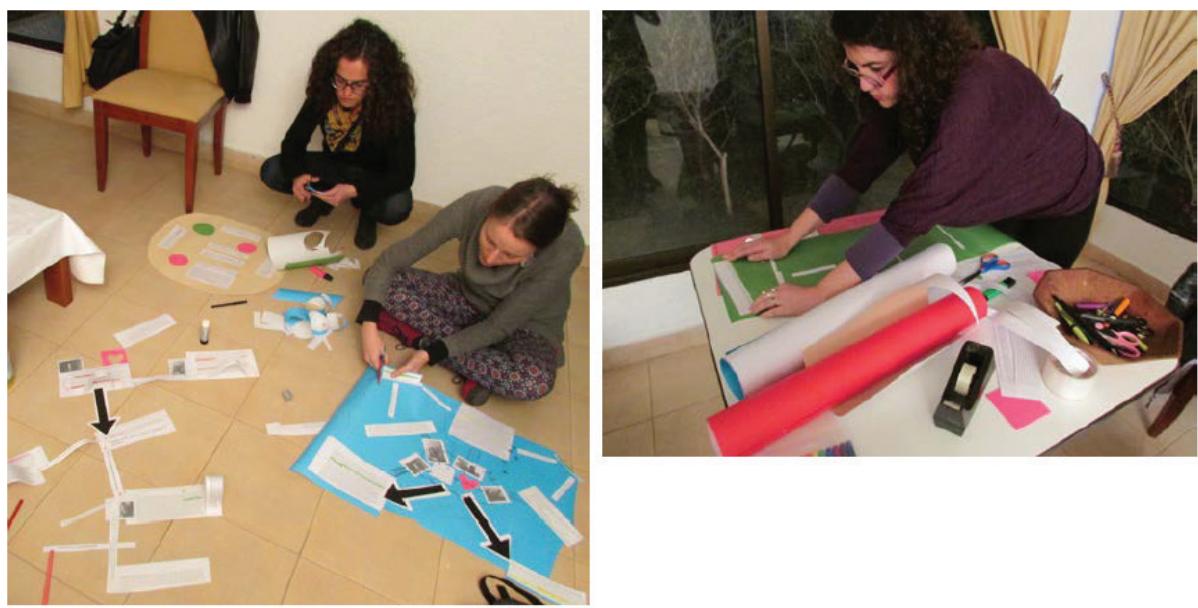

Figura 2: Profesoras desarrollando los mapas en el segundo focus group
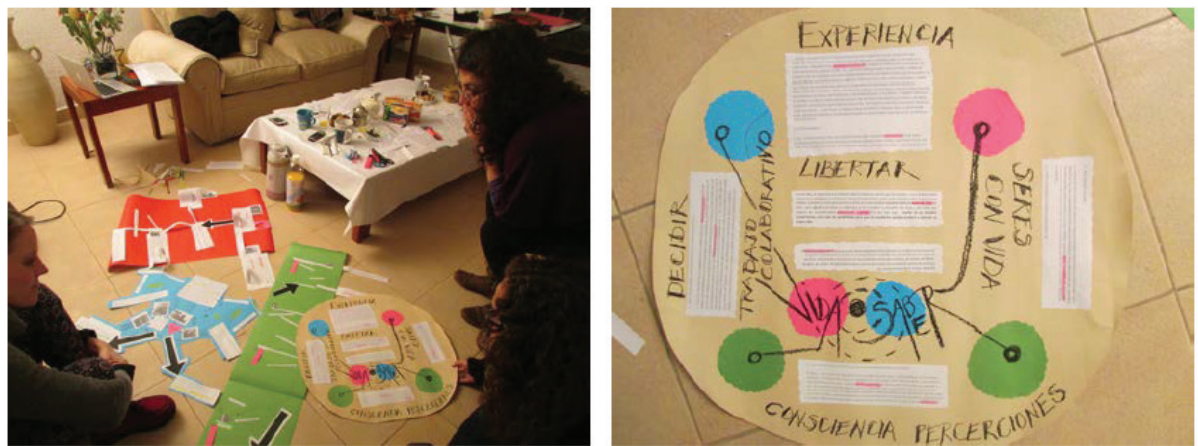

Figura 3: Profesoras compartiendo sus narrativas en segundo focus group

EMPIRIA. Revista de Metodología de Ciencias Sociales. N. ${ }^{0}$ 34, mayo-agosto, 2016, pp. 155-178. ISSN: 1139-5737, DOI/empiria.34.2016.16526 
La invitación a las profesoras fue, a partir de los relatos impresos sobre el diálogo del primer focus group, que cada una creara un mapa visual que vinculara los aspectos con los que cada una se identificó, con aquellos relatos que las otras maestras compartieron. A través de los diálogos impresos, la idea era que cada maestra relacionara sus pensamientos con los de las otras de manera libre, es decir, desde el acto de escribir, dibujar, rayar, pegar, romper, collage, etc. Algunas de las preguntas que la investigadora compartió para iniciar el trabajo fueron: (1) de qué manera, lo que compartió la otra nos resuena y permite generar un saber compartido o (2) ¿cómo las otras se van haciendo presente en nuestra forma de pensar la enseñanza? Y también (3) ¿cómo los saberes y experiencias de las otras nos resuenan y hacen re-pensar nuestra propia práctica y forma de sentirnos como mujeres artistas-docentes?

En un principio las maestras tardaron en comenzar a realizar sus narrativas visuales, ya que primero estuvieron leyendo los diversos retazos de relatos impresos dispersos sobre la mesa. Entre éstos, las participantes encontraron sus palabras y también fuero leyendo las de las otras profesoras. A partir de esa primera lectura cada una fue escogiendo los relatos para construir su mapa y, desde ahí, como si fuese un taller práctico, cada una se acomodó para comenzar a construir su narrativa visual con los diversos materiales (figura 2). Tras terminar los mapas visuales éstos fueron compartidos y las maestras contaron qué construyeron a partir de los relatos de las otras y las nuevas relaciones (figura 3).

Esta actividad fue un encuentro grupal basado en las estrategias de la IBA, donde el relato tomó un papel visual y de reflexión, ya que permitió a las maestras vincular desde lo narrativo y lo artístico, sus formas de relatarse con el de las otras maestras. Como se observa en las figuras, los relatos no solo contaban la experiencia vivida y dialogada del primero focus, sino que además éstas fueron reformuladas por las maestras al hacer de éstos otras imágenes y relaciones que mostraban nuevas formas de contarse y de saber. Esta fue una estrategia para hacer del relato individual un saber compartido, pues se construyeron narrativas visuales que vinculaban tanto los relatos personales como los de las otras maestras, generando nuevas significaciones visuales de sus saberes.

\section{EL TEXTO LITERARIO COMO PRODUCCIÓN TEÓRICA}

En este tercer apartado comparto — como último ejemplo_- otra manera de abordar el relato en la investigación social. En relación a los ejemplos anteriores, esta vez no se utilizó el relato como método para la recogida de evidencias, sino como estrategia para la reconstrucción de las historias de saber de las maestras del estudio. Otro de los objetivos de la investigación fue visibilizar el saber de las maestras a través de sus narraciones biográficas. Esto porque, en la investigación biográfica narrativa, el relato — como fenómeno y métodocumple un papel fundamental, ya que muestra otra forma de contar y representar 
la realidad y la experiencia de los sujetos con quienes investigamos (Bolívar, 2002).

A partir de las entrevistas, los relatos que compartieron estas mujeres fueron las evidencias que permitieron comprender sus tránsitos y saberes. Así, la narrativa actuó como un modo para aprender a pensarse y conocerse (Bruner, 1990). Este tipo de aprendizaje —narrativo- no es simplemente aprender desde las historias que contamos sobre nuestra vida, sino que es un proceso que sucede durante el acto de narrarse, a partir de la reflexión y la escucha (Goodson, 2010). Desde estas premisas, este estudio se alejó de las investigaciones narrativas que no entregan a las(os) participantes un papel principal en la investigación y de construcción de saber. También se buscó diferenciarse de los estudios que en los resultados no cuentan o reconocen la relación que las(os) investigadoras(os) establecen con las(os) participantes(as), como una práctica de hacer investigación ligada a lo relacional y al saber compartido (Casey, 1993; Munro, 1998; Smith, 2012).

Desde estas decisiones, tanto epistemológicas como metodológicas, luego del proceso de análisis y construcción de las categorías se buscó una forma de construir el relato final que evidenciara los aspectos relacionales de lo que implica investigar con otros(as) y comprender sus experiencias. Es decir, que pusiera en el centro aquello que se comparte en las entrevistas como espacios simbólicos y de saber. Para ello se desarrolló la técnica de las narrativas biográficas, las cuales

Se concreta en la producción de relatos modulados en los que las narraciones del entrevistado son moduladas a través de las preguntas y de los intereses del investigador, por esta razón son relatos que se centran en un(os) aspectos específicos de la vida del sujeto entrevistado que no tienen porqué coincidir con los aspectos en los cuales se centraría una narración espontánea.

La ventaja es que a través de la modulación es posible obtener narrativas de diferentes sujetos que tienen como punto focal los mismos aspectos (Barbara Biglia y Jordi Bonet-Martí, 2009: 18).

Como cuentan estos autores, a través de esta técnica los resultados son narrativizados y se textualizan de modo continuo, donde los diversos diálogos de las entrevistas se fusionan en un texto único y singular. Aquello transformó a estos relatos en narrativas subjetivas, ya que el desafío fue crear un tipo de historias que no sean homogenizantes, más bien que multipliquen miradas para ir mostrando una visión más polifónica de la realidad. Con esta técnica de reconstrucción narrativa, Bárbara Biglia y Jordi Bonet-Martí (2009) apuestan por prácticas de investigación que sean 'difractivas', las cuales vayan mostrando diversas narrativas subjetivas como método y proceso. A través de estos autores se buscaron nuevas formas de construir narrativas, para mostrar los saberes de las maestras desde maneras de escritura más compartidas y relacionales. Un tipo de narrativas que siguiendo la línea bricoleur entrecruzaran tiempos, relatos, 
acciones, voces, gestos, reflexiones, expresiones, sentidos y comprensiones.

Bárbara Biglia y Jordi Bonet-Martí (2009) trazan unas ideas claves sobre la técnica de las narraciones biográficas. Sus propuestas fueron importantes para comenzar a escribir las de esta investigación.

De su texto se rescata, como primera idea, que en vez de explicar y describir resultados contemos cuentos como parte del proceso de investigación. Este desafío también nos lleva a recordar a Jens Brockmeir (2000), quien explica que narrar no es solo describir las experiencias sino contarlas como si fueran una fábula.

La segunda idea que proponen estos autores es la de re-crear la realidad narrativizando los diálogo que se producen en los encuentros. Es decir, reproducir el fruto del intercambio entre «la entrevistadora y la entrevistada», como también mezclar los diversos materiales que se hayan ido generando entre las múltiples subjetividades. Esta idea parece interesante ya que buscaba generar un tipo de texto que permite evidenciar los aspectos relacionales de lo que implica investigar con otros(as) y comprender sus saberes. Por ello, en este estudio se pensó la idea de construir unos microrelatos que surgieran desde el diálogo incardinado entre investigadora e investigada, como el contexto donde se produjeron los discursos y saberes.

La tercera propuesta que invitan es la de construir historias que puedan ser consideradas como una performance de quien narra. Sobre este aspecto el tiempo es un factor clave, porque al narrativizar performáticamente la realidad emergen aspectos de la memoria para reconstruir lo que ocurre en el pasado. Por ende, hay un desplazamiento ficticio entre los tiempos para dar cuenta de la experiencia vivida.

Estos aprendizajes de Bárbara Biglia y Jordi Bonet-Martí (2009) se fueron cruzando con las ideas de 'escritura deconstructiva' que trabajan las posestructuralistas (Gannon y Davies, 2012). Estas feministas utilizan la escritura como un espacio disruptivo para generar sentido. Por ejemplo, Laurel Richardson (1997) representa las entrevistas transcritas y otros datos de investigación de un modo poético. Desde su propuesta expresa que la escritura ya no es solo una forma y recorrido de pensamiento, también una provocación de diferencia que nos lleva a habitar, seguir los movimientos y pasos de un texto para ir descubriendo un campo de singularidades y posibles saberes.

También rescato el trabajo de diversas autoras feministas posestructuralistas, quienes, desde sus investigaciones narrativas con profesoras, valoran los aspectos relacionales que emergen y se entrecruzan en el proceso de investigación y escritura (Petra Munro, 1998 y Kathleen Casey, 1993). Estos estudios y autoras posestructuralistas nos invitan a trabajar nuestros datos de investigación como ficción, dramas y poesías. Promueven la escritura deconstructiva como un camino para disrumpir el modo binario de la academia y abrir(nos) nuestros textos e investigaciones hacia múltiples espacios, perspectivas y sujetos (Gannon y Davies, 2012).

Por otro lado, también fue relevante revisar dos estudios que, al igual que las académicas anteriores, han dado un espacio fundamental a la relación con el 
investigado(a) y a la reconstrucción de la teoría desde un cuestionamiento por el lenguaje y las formas de representación escritas. En este sentido, el modo que Pierre Bourdieu (1999) realiza la reconstrucción narrativa en su estudio, "La miseria del mundo", fue relevante para la decisión sobre cómo se reconstruirían estas historias. El autor otorgó a la entrevista, como espacio simbólico y de saber, un papel principal como estrategia de reconstrucción teórica. El autor cuenta que el hecho de reescribir y transcribir las entrevistas es un proceso de interpretación y de análisis, donde, el ejercicio de pasar a lo escrito - tanto la oralidad de las reiteraciones, frases interrumpidas, suspiros, exclamaciones, digresiones, ambigüedades, situaciones concretas y emociones-, es un proceso donde el investigador toma decisiones, está activo, presente y pensante. Así, las entrevistas en su estudio se transforman en las reconstrucciones desde las cuales narra y describe lo acontecido con los colaboradores.

Por otro lado, en el estudio "Fragilidades vecinas" dirigido por Joan Subirats (2006), se reconstruyen narraciones biográficas de exclusión social. Éstas son desarrolladas desde un tipo de lenguaje y escritura que invita al lector a introducirse y vivir la historia de quien la cuenta. Además, previo a la narrativa de cada colaborador, el grupo de investigadores(as) relata la experiencia que implicó hacer la entrevista, desarrollando un texto que nuevamente invita al lector a conocer, desde la perspectiva del investigador, cómo fue el encuentro. Finalmente, como lectores(as) transitamos entre lo que cuenta el colaborador y el investigador(a), y es, desde ambos relatos donde uno puede situarse y comprender dichas experiencias de exclusión social.

Tras revisar los trabajos de estos y estas autoras se decidió reconstruir cuatro narraciones biográficas; una por cada maestra del estudio. A partir de las entrevistas transcritas y los relatos etnográficos del diario de campo de la investigadora, se reconstruyeron parte de los encuentros con las profesoras, como espacio de saber teórico y dialógico. El objetivo de estas historias fue mostrar cómo estas maestras han ido conformando sus saberes docentes desde la reconstrucción de los encuentros vividos como espacio de saber. En éstos, los diálogos de las entrevistas cuentan cómo las maestras construyen sus relaciones con el saber y donde la investigadora va reflexionando las principales experiencias que dan cuenta de las categorías que emergieron en el análisis. ${ }^{5}$

Así, para reconstruir las narraciones biográficas de las participantes se tomaron elementos literarios y de ficción. Éstos ayudaron a reconfigurar las escenas de las entrevistas en el tiempo y espacio concreto en las que sucedieron, intentando hacer una construcción realista de la realidad (Bourdieu, 1999). Se utilizaron elementos propios de la IBA, para crear unos textos evocativos, contextuales y vernaculares (Barone y Eisner, 2006).

Metodológicamente estas narraciones biográficas son híbridas, pues se cruzan voces, relatos, tiempos y realidades. Las narraciones biográficas están escritas como un entretejido de diversas capas y con una estructura narrativa que

5 Las categorías que surgieron tras el análisis fueron el lugar del conflicto, de los y las otras, el no saber y el agenciamiento en el saber docente de las maestras. 
se centra en la entrevista, como espacio y tiempo del encuentro.

La primera capa de estas narraciones alude a la acción que ocurre en las entrevistas con las profesoras y, por ende, a las voces de los diálogos transcritos de estos encuentros. Esta es la capa principal ya que, como han explicado Teresa Cabruja, Lupicinio Íñiguez y Félix Vázquez (2000), la narración está más ligada con la acción que la simple elaboración de una historia o testimonio. A partir de esta capa se alude al primer panorama que, según Bruner (1999), constituye el relato: la acción. Es decir, lo que acontece en un espacio donde transcurre el tiempo y habitan cuerpos que se piensan y relatan saberes. Se optó por recrear las entrevistas porque, desde una perspectiva corporeizada, se da énfasis al proceso de relación que se construye durante la investigación (Biglia y BonetMartí, 2009). De este modo, a partir de las transcripciones se reconstruyó las entrevistas, rehaciendo los diálogos como escenas de conversación que ocurrían en un eje temporal y espacial. Esto, como un modo de corporeizar que el saber no sólo se desplaza entre el lenguaje oral y las palabras, ya que las narraciones son prácticas discursivas que mediadas por las acciones, gestos, emociones y formas de ir siendo al hablar, van construyendo la realidad (Cabruja, Íñiguez y Vázquez, 2000).

Las transcripciones implicaron pasar a lo escrito la oralidad y también los gestos y los tonos con que las maestras se expresaban. Además, esas transcripciones se complementaron con las anotaciones que, posterior a cada entrevista, la investigadora hacía en su diario de campo. Como la grabadora no registraba más allá de la oralidad, se anotaban aspectos sobre el ambiente, sensaciones, interrupciones u otros sucesos que permitieran recrear lo que se había experimentado en esas escenas. Es a partir de ese vínculo dialógico que se reconstruyen sus saberes, pues, sus relatos y los diversos sucesos permiten a la investigadora ir transitando entre sus palabras para reflexionar sobre el lugar de las categorías en sus experiencias.

La segunda capa que componen estas narraciones alude a las diversas reflexiones que hace la investigadora para ir dando sentido personal, social y analítico a lo resuena en las entrevistas. Es importante señalar que las intervenciones son para hacer referencia a cómo, aquello que las profesoras expresan, alude y remite a las cuatro categorías del análisis, que fueron el lugar del conflicto, del no saber, de los otros y otras y del agenciamiento en el saber docente. Para ello la investigadora se detiene entre el diálogo y los relatos de las maestras para centrarse en cómo algunas de sus palabras, gestos y expresiones llevan a pensar en sus saberes.

La idea de introducir la voz de la entrevistadora no busca negar las subjetividades que se implicaron en este proceso, más bien es una forma de reivindicar que el o la investigadora no es un ente ajeno al proceso de estudio, sino un sujeto que se ve influenciado por su relación con los otros y otras para ir aprendiendo y generando otros saberes (Biglia y Bonet-Martí, 2009).

Para vincular las reflexiones de la investigadora con la primera capa se utilizó la estrategia de digresión, puesto que es una figura literaria que permitió congelar el espacio y tiempo real de la entrevista para colarse - dentro de 
las pausas, respiros, acciones interrumpidas de las escenas-, e introducir fragmentos "más analíticos" entornos a los relatos de las maestras.

La tercera capa es la voz de la teoría, la cual emerge a partir de la estrategia de digresión. Esta voz surge de la necesidad de invitar a otros autores y autoras, no para afirmar o fundamentar los relatos, más bien como palancas que ayudan a repensar y dialogar con las palabras y experiencias de las profesoras. Son teorías que ayudan a ir poniendo nombres a lo que piensa la investigadora sobre los relatos de las maestras, puesto que permiten reflexionar el lugar del conflicto, de los otros y otras, del no saber y los agenciamientos en sus saberes. Así, las narraciones biográficas son unas reconstrucciones etnográficas donde se va pensando con la teoría, lo que permite ir generando nuevas ideas y realidades sobre las profesoras y sus saberes.

Por último, la cuarta capa de estas narraciones alude a otros relatos que se utilizó para abrir nuevas escenas. Algunas de estas son `narraciones memorísticas' (Cabruja, Íñiguez y Vázquez, 2000) que fueron escritas en el diario de campo cuando se acompañó a las maestras a sus prácticas docentes. También se comparten intercambios de correos o recuerdos de otras entrevistas, etc. Éstas, al igual que la capa anterior, surgen desde la estrategia de digresión.

Como resultado ${ }^{6}$, estas narraciones biográficas no son escrituras lineales, pues se distinguen dos tiempos que se entrecruzan. Primero el del diálogo de las entrevistas. Es un pasado que ocurre en espacios distintos con cada maestra. El segundo tiempo es el de las digresiones. Éstas ocurren en un pasado sin tiempo, pues, son los diversos pensamientos y recuerdos que se desplazan por la cabeza de la investigadora mientras la acción del diálogo es suspendida. En estos tiempos también se van desplazando la tercera y cuarta capa.

Por último, es importante asumir los peligros que implica crear narrativas que puedan ser o caer como ejercicio de colonización. En este sentido se reconoce que este ejercicio de reconstrucción narrativa -incluso todo proceso de investigación - se constituye como una relación y práctica de poder (Munro, 1998; Biglia y Bonet-Martí, 2009; Hesse-Biber, 2012). A pesar de haber consensuado previamente con las profesoras las diversas escenas que se narrarían y compartido el proceso de escritura con ellas (enviándoles los avances para acoger sus sugerencias y correcciones), quien finalmente cuenta y enfoca las historias es la mirada de la investigadora. Por ello se intenta no enmarcar las historias con una mirada sesgada o única, sino una que es parcial, subjetiva y 'difractante', puesto que se va moviendo y desviando para abrir otras posibles visiones de la realidad. Como Biglia y Bonet-Martí (2009: 6) señalan, en estas narraciones biográficas no se buscó <<"narrar las historias de otras", sino narrativizar el diálogo que se ha producido en nuestras intersecciones y, favorecer que las narrativas propuestas puedan ser transformadas y/o subvertidas por otras subjetividades y colectividades $>>$.

${ }^{6}$ Estas narraciones biográficas son parte de la tesis doctoral "Diálogos, desplazamientos y experiencias del saber pedagógico. Narraciones biográficas de mujeres artistas-docentes” la cual será publicada en Septiembre del 2016. 


\section{CONCLUSIONES}

En este escrito se ha compartido el uso de la narrativa en esta investigación doctoral, el cual ha estado ligado a elementos propios de la IBA para mostrar otras formas de utilizar el relato en estudios de la experiencia educativa. Se utilizó como método, fenómeno de estudio y como reconstrucción teórica en las narraciones biográficas.

En primer lugar, en las entrevistas, la construcción de relatos etnográficos actuaron como estrategias desencadenantes que ayudaron a que las maestras pudieran reflexionar sobre sus saberes experienciales y, desde estas conversaciones, generar nuevos relatos de sus saberes.

En segunda instancia, el relato en el focus group fue utilizado como una forma para reflexionar sobre si mismas y las otras. Por otro lado, también se utilizó el relato para construir narrativas visuales que pudieran vincular sus saberes y los relatos compartidos. En ese sentido, lo textual toma un carácter visual que permite mostrar nuevas formas de producir conocimiento, donde la imagen creada es una evidencia que contiene teoría y conceptos (López Canto, 2015).

A través del tercer ejemplo se compartió cómo se crearon narraciones biográficas. Estos relatos, que eran fragmentos y escenas de los encuentros presenciales, fueron re-contextualizados en un espacio a través de herramientas literarias como el diálogo, la digresión, la descripción densa del espacio, otros personajes que intervienen, etc. Vincular los relatos de historia con el análisis y reinterpretación sociológica transforma, a la simple transcripción de la entrevista, en una narración biográfica subjetiva. Y una historia, además, que es relacional, pues enmarca lo que significa construir el conocimiento desde un espacio que es dialógico y compartido.

A modo de colofón, a pesar de que con estos tres modos de utilizar el relato en una investigación narrativa se buscaba priorizar el relato de saber de las participantes, es importante señalar que es ingenuo creer que a través de estas historias se da voz a las profesoras o se empodera 'voces oprimidas'. Como señala Petra Munro (1998), la liberación o transformación no es una característica inherente de esta metodología, pues aunque las investigaciones feministas busquen empoderar y promover un cambio social en las mujeres (Sharlene Nagy Hesse-Biber, 2012), es iluso dar por sentado ese desafío y menos pensar que la metodología narrativa lo garantiza. Más bien, al igual que HesseBiber, podemos preguntarnos en qué sentido los y las investigadoras damos voz y hasta qué punto no es un privilegio. A través de esta metodología podemos mostrar la voz, pensamientos y acciones de las profesoras, pero no dárselas. Por ello, ante este tipo de metodologías y estrategias es importarte asumir y cuestionar los peligros que implica crear narrativas que puedan ser o caer como ejercicio de colonización (Munro, 1998; Biglia y Bonet-Martí, 2009; HesseBiber, 2012).

Además de valorar los aportes que las estrategias narrativas tuvieron en la experiencia del saber, de quienes participaron en esta investigación (García- 
Huidobro, 2015b), también se comparten las contribuciones que este tipo de estrategias narrativas aportan al campo de la investigación social.

En primer lugar, priorizar el relato, la expresión oral y escrita como método de recogida de evidencias y de producción teórica, intenta escapar de la normatividad académica difuminando fronteras entre lo literario y lo científico o entre la ficción y la investigación social (Richardson y St. Pierre, 2005). Además de rescatar relatos que pueden quedar al margen de una investigación social, podemos contarlos de un modo que permite reconstruir lo vivido de manera más natural, situándose como una 'ontología realista-materialista' (Denzin y Lincoln, 2011).

Segundo, esta metodología aporta nuevas ventanas para producir saberes desde lo dialógico y polifónico. Dar sitio primordial al relato ayuda a imaginar espacios donde los saberes pueden nacer de actitudes más dialógicas y en los recorridos de pensarse con otros y otras (Hernández y Rifà, 2011). Los conocimientos se van desplegando de las conversaciones con las maestras y el modo en que la investigadora reflexiona sobre ello.

Además son estrategias que permiten situar lo corpóreo en la investigación, porque desde el relato se acoge la experiencia del ambiente y del movimiento como propios. También la emotividad, sentimientos, diálogo y gestos como espacios y expresiones de saber. De este modo el relato permite generar narraciones verosímiles que dan cuenta de lo vivido "como si se hubiera estado allî" (Hernández y Rifá, 2011: 15).

Por otro lado, al utilizar el relato como estrategia, el o la investigadora se sitúa de otra manera en la investigación. Primero, no es quien da voz a los(as) participantes y no actúa como un simple acto o capricho narcisista de contarse, sino que es una práctica compleja y rigurosa donde el o la investigadora junto a los y las participantes ponen al descubierto sus posiciones reflexivas. En este sentido, utilizar el relato de diversas maneras en la investigación no difumina las voces de los y las participantes, sino que las revaloriza al entrecruzarlas y reflejarlas con otras. He aquí el valor 'difractante', ya que al utilizar el relato como estrategia de recogida y construcción teórica, permite construir narraciones polifónicas que generan nuevos sentidos y realidades.

Por último, este estudio muestra cómo el método de relatarse se despliega como una práctica política para leerse subjetivamente. Reflexionar sobre la experiencia posibilita dar un nuevo sentido a las vivencias, relaciones y tránsitos de los saberes profesionales, ya que relatarse es abrir posibilidades de subjetividad. Este proceso, que remite al aprendizaje narrativo que explora Ivor Goodson (2010), no es simplemente aprender desde las historias que contamos sobre nuestra vida, sino que es un aprendizaje que sucede durante el proceso de narrar. Por ello, el proceso de reflexión y escritura vivido en esta investigación es un aprendizaje que también, Jean Clandinin (2007), ha llamado saber narrativo.

A través de las formas de contarse de las maestras este estudio muestra que el sentido y la fuerza de los espacios narrativos son experiencias que impulsan a explorarse y nombrarse desde múltiples posicionamientos, donde va circulando la subjetividad política del saber (Martínez y Cubides, 2012). Es 
en la inmediatez del pensarse y relatarse donde se genera y negocia un saber otro, que era distinto al saber que narraban. En las entrevistas, mientras las profesoras iban relatando sus distintos recorridos de vida como saberes, el modo de pensarse y decirse también se iba desplegando como otros desplazamientos. Esto visibiliza cuan compleja y rica es la práctica de narrarse, ya que a partir del cómo estas profesoras se fueron contando y expresando, se señala que el saber pedagógico no son relaciones abstractas o que solo se va conformando desde el discurso oral o escrito, sino que está ligado al cuerpo como la 'decibilidad' de la propia experiencia. Esto refiere a la práctica del saber dialógico, como un espacio desde el cual hacemos y hablamos con otros y otras. Por ende, el saber que emerge cuando pensamos y nos narramos está encarnado y se constituye como una acción lingüística de los desplazamientos que vamos siendo al nombrarnos. Esta idea me remite a lo que Donald Schön (1998) describe como nuestro pensamiento en acción, pues en ese espacio reflexivo se van encarnando y moviendo los saberes.

Por ello que en las historias, lo que estas profesoras decían y hacían a la vez, así también lo que decían y el cómo lo expresaban se desplegaba como prácticas de saber políticas-subjetivas. Esta idea nos recuerda lo que Rossi Braidotti (1991: 8) ha llamado "las raíces corporales del proceso de pensamiento", pues remiten a cómo en nuestra forma de reflexionarnos, cuestionarnos y contarnos emerge un ir sabiendo en la acción. Al relatarnos, nuestra experiencia de saber se encarna y materializa, y las fisuras de nuestros pensamientos se convierten en espacios donde fluyen sentidos de subjetividad.

\section{BIBLIOGRAFÍA}

ADAMS, J. (2003): "The Artist-Teacher Scheme as Postgraduate Professional Development in Higher Education”. International Journal of Art \& Design Education, 22, 2, pp. 183-194.

BARONE, T. Y EISNER, E. (2006): “Arts-Based Educational Research”, en Green, J., Grego, C. y Belmore, P. (Eds.) Handbook of Complementary Methods in Educational Research. New Jersey, AERA, pp. 95-109.

BIGLIA, B. Y BONET-MARTÍ, J. (2009): "La construcción de narrativas como método de investigación psicosocial. Prácticas de escritura compartida". Forum Qualitative Sozialforschung / Forum: Qualitative Social Research, 10,1, 73 párrafos.

BOLÍVAR, A. (2002): “¿De nobis ipsis silemus?”: Epistemología de la investigación biográfico-narrativa en educación. Revista Electrónica de Investigación Educativa, 4,1, pp. 1-26.

BOURDIEU, P. (1999): La miseria del mundo. Madrid, Akal.

BRAIDOTTI, R. (1991): Patterns of Dissonance. A study of women in contemporary philosophy. New York, Routledge.

BROCKMEIER, J. (2000): “Autobiographical Time”. Narrative Inquiry, 10,1, pp. 51-73.

BRUNER, J. (1990): Acts of Meaning. Londres, Harvard University Press.

BRUNER, J. (2004): “Life as Narrative”. Social Research, 71,3, pp. 691-710.

BURR, V. (2003): Social Constructionism. New York: Routledge. 
CABRUJA, T., ÍÑIGUEZ, L., VÁZQUEZ, F. (2000): “Cómo construimos el mundo: relativismo, espacios de relación y narratividad". Anàlisi, 25, pp. 61-94

CASEY, K (1993): I Answer with My Life: Life Histories of Women Teachers Working for Social Change. Londres, Routledge.

CHARMAZ, K. (2006): Constructing grounded theory. A practical guide through qualitative analysis. Londres, Sage.

CHARMAZ, K. (2012): “The Power and Potential of Grounded Theory". Medical Sociology online, 6, 3, pp. 1-15.

CLANDININ, J. \& CONNELLY, M. (1990): “Stories of experience and Narrative Inquiry". Educational Researcher, 19, 5, pp. 2-14.

CLANDININ, J., \& CONNELLY, M. (1995): "Relatos de experiencia e investigación narrativa", En Larrosa (Ed.) Déjame que te cuente. Ensayos sobre narrativa y educación. Barcelona, Laertes, pp. 11-59.

CLANDININ, J. \& CONNELLY, M. (2000): Narrative inquiry: experience and story in qualitative research. California, Jossey-Bass.

DENZIN, N., LINCOLN, Y. (2011). The Sage handbook of qualitative research. California: Sage.

CLANDININ, J. (2007): Handbook of Narrative Inquiry. Mapping a Methodology. California: Sage.

EISNER, E. (1998): El Ojo ilustrado: indagación cualitativa y mejora de la práctica educativa. Barcelona, Paidós.

FREIRE, P. (2002): Pedagogía de la autonomía. Saberes necesarios para la práctica educativa. Buenos Aires, Siglo veintiuno

GANNON, S., BRONWYN, D. (2012): "Postmodern, Post-structural and Critical Theories". En Hesse-Biber, S. (Ed.) Handbook of Feminist Research: Theory and Praxis. Thousand Oaks: Sage, pp. 65-91.

GARCÍA-HUIDOBRO, R. (2013): "Situando el lugar del otro en mi investigación. Trabajar con mujeres chilenas artistas y docentes, como parte de mi propia experiencia”, En AUTODOC, Grupo autogestionado del Doctorado en Artes y Educación de la Universidad de Barcelona. (Ed.) Compartir y dialogar en torno a las experiencias del proceso de investigación. Barcelona, AUTODOC, pp. 26-31.

GARCÍA-HUIDOBRO R. (2014): "Compartir experiencias entre mujeres, artistas y docentes a través de herramientas virtuales". Revista Digital do LAV, 7,2, pp. 214227.

GARCÍA-HUIDOBRO, R. (2015a): "El espacio entre. Saberes docentes de mujeres artistas-docentes”. En Márquez, M. J., Prados, M. E., Padua, D. Historias de vida en educación. Voces Silenciadas. Universidad de Almería, pp. 126-138.

GARCÍA-HUIDOBRO, R. (2015b): "Comprender el saber docente desde la metodología de las historias de vida”. REIDOCREA, 4, pp. 139-147.

GERGEN, K. (1996): Realidades y relaciones. Aproximaciones a la construcción social. Barcelona, Paidós

GOODSON, I. (2010): Narrative Learning. New York, Routledge.

HERNÁNDEZ, F. (2008): "La investigación basada en las artes. Propuestas para repensar la investigación en educación", Educatio Siglo XXI, 26, pp. 85-118.

HERNÁNDEZ, F., RIFFÀ, M. (coord.) (2011): Investigación Narrativa y Cambio Social. Barcelona: Octaedro.

HERNÁNDEZ, F. (s/f): "Mi trayectoria por la perspectiva narrativa de investigación en educación”. Documento inédito entregado a los y las estudiantes del máster Artes y Educación: Un enfoque construccionista de la Universidad de Barcelona. 
HESSE-BIBER, S.G. (2012): "Exploring, Interrogating, and Transforming the Interconnections of Epistemology, Methodology, and Method". En Hesse-Biber, S. (Ed.) The handbook of feminist research theory and praxis. Londres: Sage. pp. 2-26.

HUBERMAN, M. (1989): "The professional life cycle of teachers". Teachers College Record, 91,1, pp. 31-57.

HUSS, E. (2005): "Researching creations: Applying arts-based research to Bedouin women's drawings". International Journal of Qualitative Methods, 4, 4, Article 4.

LÓPEZ CANTO, F. (2015): "La simulación y representación de modelos y teorías científicas mediante imágenes". Thémata, 51, pp. 271-288.

MARTÍNEZ, M.C., CUBIDES, J. (2012): “Acercamientos al uso de la categoría de 'subjetividad política' en procesos investigativos". En Piedrahita, C., Díaz, Á., Vommaro, P. (Comp.) Subjetividades políticas: desafíos y debates latinoamericanos. Bogotá: Universidad Distrital Francisco José de Caldas, pp. 169-190.

MASON, J. (2002): "Qualitative interviewing: Asking, listening and interpreting", en. May T. (Ed.) Qualitative research in action, London, Sage, pp. 225-242.

MUNDAY, J. (2014): “The Practice of Feminist Focus Groups". En Hesse-Biber, S. (Ed.) Feminist Research Practice. (2a ed.) Boston, Sage. pp. 166-184.

MUNRO, P. (1998): Subject to Fiction. Women Teacher's Life History Narratives and the Cultural Politics of Resistance. Philadelphia, Open University Press.

RICHARDSON, L. (1997): Fields of Play: Constructing an Academic Life. New Jersey, Rutgers University Press.

RICHARDSON, L., ST. PIERRE, E. (2005): "Writing: A Method of Inquiry". En Denzin, N., Lincoln, Y. (Ed.) The Sage handbook of qualitative research (3rd ed.), Thousand Oaks, CA, Sage, pp. 959-978.

RICHERT, A. (1993): "Voice and Power in Teaching and Learning to Teach", En Valli, L. (Ed.) Reflective Teacher Educator. Cases and Critics, New York, University of New York Press, pp. 187-197.

SCHÖN, D. (1998): El profesional Reflexivo. Cómo piensan los profesionales cuando actúan. Barcelona, Paidós.

SCLATER, D. (2003): “The arts and narrative research". Qualitative Inquiry, 9, 4, pp. 621-625

SMITH, J. (2012): "Reflections on using life history to investigate women teachers' and career decisions". Qualitative Research, 12, 4, pp. 486-503.

SUBIRATS, J. (2006): Fragilidades Vecinas. Narraciones biográficas de exclusión social urbana. Barcelona, Icaria.

TARDIF, M. (2004): Los Saberes del docente y su desarrollo profesional. Madrid, Narcea. 
